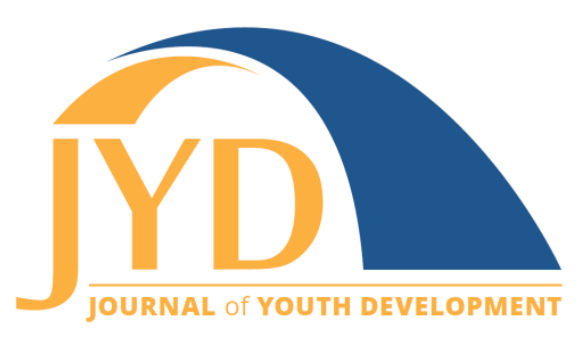

http://jyd. pitt. edu/ | Vol. 14 Issue 1 DOI 10.5195/jyd.2019.723 | ISSN 2325-4017 (online)

\title{
Strategies for Gaining Access to Deliver Sport Programs With Highly Vulnerable Youth
}

\author{
Jenn M. Jacobs \\ Northern Illinois University \\ jmjacobs@niu.edu \\ Zachary Wahl-Alexander \\ Northern Illinois University \\ zwahlalexander@niu.edu \\ Timothy Mack \\ Northern Illinois University \\ z1713481@students.niu.edu
}

\begin{abstract}
Sport programs have been widely studied for their efficacy in helping youth develop important social, psychological, and physical skills. Extensive research has explored the challenges related to design, implementation, and evaluation of sport programs with a developmental focus. However, when designing sport programs specifically tailored for youth from vulnerable backgrounds, the challenges become multiplied, particularly when accounting for barriers that exist before the program starts. The following article describes best practices for gaining access to non-traditional, hard-to-access environments, such as foster care systems, juvenile detention centers, youth residential mental health facilities, and programs situated in high-risk communities. Recommendations are provided for the initial phase of sport program development for vulnerable populations, including protecting youth, choosing appropriate sport content, and addressing barriers in the research process. Generally, these best practices are applicable for the development of any youth program. However, this article provides context-specific guidance and precautions that should be considered to protect and foster the well-being and welfare of youth from highly vulnerable populations.
\end{abstract}

Key words: sport-based youth development, at-risk youth, partnerships

Researchers and practitioners alike can agree that in order to move the field of youth development forward, high quality, innovative, and evidence-based interventions with diverse

(cc) EY New articles in this journal are licensed under a Creative Commons Attribution 4.0 License. This journal is published by the University Library System, University of Pittsburgh and is cosponsored by the University of Pittsburgh Press. The Journal of Youth Development is the official peer-reviewed publication of the National Association of Extension 4-H Agents and the National AfterSchool Association. 
Vulnerable Youth Programs

youth populations are essential. Sport has been proposed as an ideal context that has seen success with fostering life skill development for a variety of youth (Danish \& Nellen, 1997). Over the last several decades, many sport-based youth development programs have achieved various outcomes such as increasing physical activity levels (Schwamberger \& Wahl-Alexander, 2016), fostering social skills (Hellison, 2011), and increasing out-of-program fitness behaviors and health outcomes (Wahl-Alexander, Hastie, \& Johnson, 2018). These interventions have primarily taken place within physical education programs, after-school contexts, and community-based settings where practitioners may experience minimal challenges with fostering productive partnerships or gaining access to the site. Generally, these youth-based entities are able and open to partnering with outside personnel based on a shared dedication to positively impacting students' physical and mental health.

However, as researchers and practitioners, we should continually feel compelled to reach those youth populations that are not readily accessible, even if that means there are significant barriers in the process of gaining access. Often, these youth have the greatest needs and could potentially gain the most life-altering benefits and outcomes. At the same time, it is these contexts that return significant challenges in navigating the appropriate steps to building collaborations, coming to a consensus on program aims, and protecting the welfare and safety of all those involved (Harper \& Carver, 1999).

The following article is based on our experience initiating a fitness leadership program within a male juvenile detention facility. From our first contact with the juvenile detention facility, this program took approximately seven months to initiate. The initiation process included several meetings with stakeholders from the facility, preparation of the research review board application, several iterations of revisions/clarifications on the research approval process (with both our university and the juvenile facility), as well as numerous site visits to familiarize ourselves with the facility context and refine/revise our program aims. While not the focus of this paper, our program aims were to help youth build important life skills through sport, as well as develop healthy fitness behaviors and habits that they could use outside of the program, and outside of the facility upon their release. As a result, the purpose of this article is to offer strategies to researchers and practitioners who would like to pursue projects working with youth in non-traditional, hard-to-access environments, such as foster care systems, juvenile detention centers, youth residential mental health facilities, or high-risk communities where youth and practitioner/researcher safety is not definite. Specifically, early phase tactics, assurances for protecting youth, considerations for program content, and strategies for conducting in-program research are offered. 
As we share these experiences and lessons learned in the process of initiating our program, it is important to acknowledge our background, positions, and prior experiences that led to this project. As junior faculty in a sport sciences department at a regional university, our research areas overlap in regard to sport and physical activity program development for youth from marginalized backgrounds. In addition to our faculty status, we both have more than a decade of experience holding leadership positions in school and out-of-school youth programs. Additionally, we have experience delivering programs specifically for highly vulnerable youth populations. One co-author participated in a supervised graduate project teaching physical education to young women in a maximum-security prison located in the southern United States, while the other has implemented and evaluated programs in a highly gang-populated part of a major city. While not a requirement, we were deliberate in undertaking this project based on prior professional experiences and qualifications.

\section{Early-Phase Tactics}

Shortly after idea conception, it is important to connect with the youth facility of interest to determine if there is mutual appeal to move the project forward. Given that many organizations serving vulnerable youth are scarcely understaffed and short on resources (Armstrong \& Jackson, 2005), we suggest allowing significant time to navigate facility communication systems in order to connect with the appropriate person who is in a decision-making position. In our experience, researching the facility website and contacting multiple individuals on their personnel listings is advisable for moving the idea forward. Although job titles can vary based on the type of organization, oftentimes director positions related to "youth activities," "leisure time" or "program coordinator" would be beneficial individuals to initially contact and propose the program idea.

Once the initial introduction is made, it is advisable to share how your intended project can move the organization's mission and current initiatives forward. Understanding the mission and vision of the facility is essential for gaining multi-level administrative buy-in. With this said, being prepared for staff turnover and having to re-introduce your program mission to multiple staff members is likely (Mor Barak, Nissly, \& Levin, 2001). Through these conversations, it is important to establish a timeline up front, one that balances reasonable expectations on the part of the practitioner, while providing a consistent, sustained program that can positively impact youth. In these initial conversations, it is also crucial to be forthcoming on what resources will be shared, and specifically, which fall under the responsibility of the facility or will 
Vulnerable Youth Programs

be supplied by the university/partnering entity. While these can be sensitive topics to discuss, it is important to understand that resources are limited in many youth-serving organizations, and this is only exacerbated in programs that rely on government funding or fall subject to budget limitations. In our experience, we provided a list of all equipment and resources we would supply, grant outlets we intended to pursue for additional support, and a request for specific resources we hoped the facility could contribute.

\section{Protecting Vulnerable Youth}

Gaining access to vulnerable youth populations requires intentional and deliberate reflection on how best to protect these individuals from further harm than they have already experienced. Youth with vulnerable backgrounds often suffer from psychosocial problems, trauma, loss of caregivers, poverty, and social isolation (Zweig, 2003); therefore, programs should be designed and implemented thoughtfully with these factors in mind. First and foremost, every decision relating to program design should be informed by putting youth welfare and wellness above all. At times, this means sacrificing aspects of teaching models that are known to be best practices with youth. For example, it might not always be advisable to emphasize skill development during activities and games, as is often a desired outcome of sport-based programs (Metzler, 2017). In our program, part of our mission was to engage youth in healthy sport experiences, so we initially chose not to emphasize technical sport skills, such as proper dribbling form during basketball or throwing form in football. However, after we established trusting relationships with youth, we did look for opportunities to challenge them and provide suggestions for improvement in their techniques. Similarly, it is recommended that early in the program, instructors limit critique or feedback, as youth may be highly sensitive to being in evaluative situations around their peers or instructors and this may cause further harm or isolation (Ewart, Jorgenson, Suchday, Chen \& Matthews, 2002). To address this, it is recommended that practitioners spend considerable time participating in an "immersion phase," where before the program commences, steps are taken to familiarize oneself with the context, facility setting, youth backgrounds, and rules and routines held by youth. In our case, we committed to several hours per week, over the course of the month, spending time with youth during their unstructured recreation time. This time was spent getting to know them, playing cards or board games, and sharing personal information about likes, interests, etc.

Another important factor in designing youth programs for vulnerable populations is to consider cross-cultural differences between program staff and youth. Specifically, seeking to understand cultural language and terminology youth use in their life is important for fostering respect, 
Vulnerable Youth Programs

understanding, and consistency. For example, if certain facility codes or behavioral levels are used, these might be a way to encourage youth to work toward goals that align with their facility culture. In our experience, we celebrate when a program member reaches, "A level" based on their behavior outside of the program, as well as invite youth to disclose when they receive disciplinary "tickets" for violating facility rules. In other facilities, this may be demonstrated by having conversations with facility staff and learning what individual achievements or breakthroughs are publicly shared that can be acknowledged in the program setting. Learning other important cultural aspects such as music or hobbies are opportune ways for program staff to connect with youth and provide youth an opportunity to teach them about their interests. The juvenile facility we worked in was proximal to a large city where many up and coming hip hop artists came from. We saw their shared musical interests as opportunity to empower the youth to be experts on something, teach us about the musicians, play their music during activity times and eventually encourage them to self-express by creating their own artistic products.

Given that youth from vulnerable populations may have a distrust of organizational figures (Wilkinson, Beaty, \& Lurry, 2009), it is also important to distinguish the program from "the system," or what they may view as the very negative forces affecting their lives. When initiating a program in a juvenile detention center, it was important for us to establish that we were "outsider" university individuals not associated with or employed by the detention center. Especially in environments employing security officers, youth may have extreme distrust or feelings of betrayal directed at these personnel, which may serve as a barrier for them choosing to participate in a sport program they know will be supervised. As a result, it is critical to consider their vulnerability from all angles, including while they are presently participating in the program. For example, in our juvenile detention fitness leadership program, we wanted to offer youth the chance to reflect on what they got out of the program through journaling, drawing, writing poetry, or creating song lyrics. What we overlooked was that while they are housed in their facilities, no property is private, and all their materials are subject to be searched (and read) by security personnel. Therefore, it was impossible to assure confidentiality, or that their private thoughts and reflections would not be used inappropriately by their peers or superiors. While youth journaling has previously been viewed as hallmark strategy for enhancing program impact, in this case, the feature ultimately threatened a negative effect on youth welfare.

Finally, as is a best practice in initiating any program with youth, it is critical for program staff to have honest and thoughtful reflections on their biases and assumptions. Especially when cross cultural differences (e.g., race, class, gender) are present, youth from marginalized 
Vulnerable Youth Programs

backgrounds are susceptible to feeling guarded and vulnerable when new adult figures enter their lives (Cauce et al., 2002). Based on this reality, program staff are encouraged to consider their own power and privilege thoughtfully. One way to address this is through relationshipbuilding, or what many researchers have determined to be the foundation of successful positive youth development programs (Larson, 2006; Lerner, Almerigi, Theokas, \& Lerner, 2005). Key relationship-building strategies include learning names, taking an interest in youths' hobbies, following through on commitments, and helping them envision possible futures for themselves (Laursen, \& Birmingham, 2003). In our program setting, we used the month prior to the program for relationship-building through structured "getting to know you" interviews that asked about their goals, hobbies, and struggles. During these interviews, we also shared our personal responses to the interview prompts to better foster trust and openness from both parties.

\section{Choosing Appropriate Program Content}

When designing any youth program, it is important to consider the relevance, suitability, and safety of program content for the desired population. Careful attention to youths' age and developmental levels are deemed necessary for delivering a successful program. Specifically, when working with youth in uniquely vulnerable settings, special modifications may be necessary. Knowing the population's risk factors can help inform decisions. For example, when working with youth at mental health facilities, modifications to sport program content may include minimizing physically tolling activities, as physical limitations may be present. In youth populations with aggressive tendencies, consider risks associated with contact sports or activities that require equipment that may be used to harm another individual (e.g., bats, sticks, etc.). Furthermore, in many facility environments, space and staffing are limited and youth participation may be inconsistent, so program staff are encouraged to have back-up plans for all activity sessions. In our experience, we prepared our curriculum with maximal flexibility to address unforeseen changes. This included having several "go-to" teambuilding activities that required minimal to no equipment and games that could be modified based on the number of participants that were present on any given day.

When devising program content, it should be acknowledged that there is a whole field of research exploring how sport-based programs that include a life skill emphasis have seen great success with youth from marginalized backgrounds. Several teaching models (e.g., social and emotional Learning framework, Gordon, Jacobs, \& Wright, 2016; teaching personal and social responsibility through sport, Hellison, 2011) and national sport-based youth programs (e.g., 
Vulnerable Youth Programs

SUPER: Sports United to Promote Education and Recreation; Brunelle, Danish, \& Forneris, 2007; The First Tee Program; Weiss, Stuntz, Bhalla, Bolter, \& Price, 2013) have followed a life skill development approach and documented changes in positive developmental outcomes for youth. While sport-based youth development programs inherently seek to foster life skills growth for youth from all backgrounds, it can be viewed as a critically missed opportunity if the life skills approach is not utilized in sport programs designed specifically for vulnerable youth, as their needs may be greater. Prior program evaluations have seen successes in similar sport programs fostering connectedness among gang-affiliated youth (Buckle \& Walsh, 2013) and helping to envision possible futures for disenfranchised youth (Walsh, 2008). With these documented findings, adopting a life skills approach is an ideal way to multiply the impact of a program, and should therefore be considered integral for program development.

\section{If Research is Involved}

As stated previously, there has been a plethora of research sharing best practices and evidencebased tactics for implementing sport-based youth development programs. However, it is equally important for programs, especially novel or innovative ones, to inform research. For programs considering a research component, we offer several recommendations based on the lengthy and challenging process we experienced. While our context represents a unique setting within its own governing bodies (i.e., university review board and juvenile detention center), we expect these challenges to be consistent across agencies that are tasked with protecting the welfare of vulnerable youth.

First, it is recommended to begin the process of seeking research approval at least 6 months in advance of the intended program start date. Given that permissions will likely be necessary across two governing bodies (i.e., university review board and facility board), it is advisable to allow significant time for ongoing consultations with both entities, concurrently. One strategy is to consult with the university board first and address any foreseeable challenges that may arise while conducting research with a vulnerable population. In our case, we experienced feedback that we were requesting information on topics the research board had not addressed before, and they were unsure where to retrieve answers for some inquiries. Ultimately, they had to bring in an external expert on prison populations to review our research materials. Therefore, allowing significant time for back-and-forth proved to be successful while board members initiated discussions with outside experts. 
Vulnerable Youth Programs

One suggestion for early conversations with university board personnel is to prepare a comprehensive list of data sources to be utilized, with the reality that scaling back will likely be an outcome central to the process. While this can be viewed as limiting, the primary purpose of a university research board is to assure ethical practices are being followed that protect the welfare of research participants above all. Based on this, it is comforting to know research boards are designed to protect the development and well-being of the very individuals the proposed program is seeking to benefit as well. This alignment in values is key to recognize in this lengthy process.

In addition to ongoing clarifying conversations with the university review board, it is necessary to present a comprehensive outline of research procedures to the facility as well. Given the variety of educational backgrounds individuals on this governing board may possess, we advise preparing tailored proposals for stakeholders of varying levels (e.g., onsite directors, regional or state level administrators, etc.). Research protocol should be prepared in non-academic language so maximum transparency and clarity is assured. While both university and facility entities should prioritize youth welfare above all, researchers should still be prepared for incongruent requests or decisions between university stakeholders and program facility personnel. To address this, consider preparing a memorandum of understanding between the university and facility in order to lay out all agreements and parameters of the research project. While certain elements of any youth program development process will be lengthy, it is especially important to remain patient and committed when attempting to initiate a program serving vulnerable youth that includes a research component.

\section{Conclusion}

Those working with youth populations are already aware of the multitude of challenges associated with initiating a program. Much planning and persistence is needed to identify mutual positive outcomes, foster buy-in from partners, and design a program customized to youths' wants and needs. These tasks are typical in any program development phase. However, when attempting to gain access to working with vulnerable youth populations, the challenges are multiplied. In these settings, resources are more limited and extra precautions are necessary to assure and protect the well-being of youth. Despite this, it is important to remember that along with all the extra considerations necessary for developing a program for underserved youth, the potential for positive impact with this population is exponentially increased. Giving kids from vulnerable backgrounds a chance to thrive in a psychologically and physically safe place is an important pursuit for practitioners and researchers to embark on. 


\section{References}

Armstrong, T. L., \& Jackson, L. (2005). Overrepresentation of minorities in youth correctional confinement in the United States: A promising aftercare approach for ameliorating this problem. Youth Crime and Juvenile Justice, 1-30.

Brunelle, J., Danish, S. J., \& Forneris, T. (2007). The impact of a sport-based life skill program on adolescent prosocial values. Applied Developmental Science, 11(1), 43-55.

Buckle, M. E., \& Walsh, D. (2013). Teaching responsibility to gang-affiliated youth. Journal of Physical Education, Recreation, and Dance, 84(3), 53-58. doi:10.1080/07303084.2013.757193

Cauce, A. M., Domenech-Rodríguez, M., Paradise, M., Cochran, B. N., Shea, J. M., Srebnik, D., \& Baydar, N. (2002). Cultural and contextual influences in mental health help seeking: A focus on ethnic minority youth. Journal of Consulting and Clinical Psychology, 70(1), 44.

Danish, S. D., \& Nellen, V. J. (1997). New roles for sport psychologists: Teaching life skills through sport to at-risk youth. Quest, 49(1), 100-113. doi:10.1080/00336297.1997.10484226

Ewart, C. K., Jorgensen, R. S., Suchday, S., Chen, E., \& Matthews, K. A. (2002). Measuring stress resilience and coping in vulnerable youth: The social competence interview. Psychological Assessment, 14(3), 339.

Gordon, B., Jacobs, J.M., \& Wright, P.M. (2016). Social and emotional learning through a teaching personal and social responsibility based after-school program for disengaged middle-school boys. Journal of Teaching in Physical Education, 35, 358-369. doi:10.1123/jtpe.2016-0106

Harper, G. W., \& Carver, L. J. (1999). "Out-of-the-mainstream" youth as partners in collaborative research: exploring the benefits and challenges. Health Education \& Behavior, 26(2), 250-265. doi:10.1177/109019819902600208

Hellison, D. R. (2011). Teaching personal and social responsibility through physical activity. Champaign, IL: Human Kinetics.

Larson, R. (2006). Positive youth development, willful adolescents, and mentoring. Journal of Community Psychology, 34(6), 677-689. doi:10.1002/jcop.20123

Laursen, E. K., \& Birmingham, S. M. (2003). Caring relationships as a protective factor for at-risk youth: An ethnographic study. Families in Society, 84(2), 240-246. doi:10.1606/1044-3894.101

Lerner, R. M., Almerigi, J. B., Theokas, C., \& Lerner, J. V. (2005). Positive youth development a view of the issues. The Journal of Early Adolescence, 25(1), 10-16. doi:10.1177/0272431604273211

Metzler, M. (2017). Instructional models in physical education. New York, NY: Routledge.

Mor Barak, M. E., Nissly, J. A., \& Levin, A. (2001). Antecedents to retention and turnover among child welfare, social work, and other human service employees: What can we learn from past research? A review and metanalysis. Social Service Review, 75(4), 625-661. doi:10.1086/323166 
Journal of Youth Development | http://jyd.pitt.edu/ | Vol. 14 Issue 1 DOI 10.5195/jyd.2019.723

Vulnerable Youth Programs

Schwamberger, B. \& Wahl-Alexander, Z. (2016). Children's activity levels and lesson context during summer swim instruction. The Physical Educator, 73 (4), 733 - 744. doi:10.18666/TPE-2016V73-I4-6977

Wahl-Alexander, Z., Hastie, P., \& Johnson, N. (2018). Using a fishing sport education season to promote outside engagement. Journal of Physical Education, Recreation and Dance. 89(7), 28-33. doi:10.1080/07303084.2018.1490222

Walsh, D. (2008). Helping youth in underserved communities envision possible futures: An extension of the teaching personal and social responsibility model. Research Quarterly for Exercise and Sport, 79(2), 209-221. doi:10.1080/02701367.2008.10599484

Weiss, M. R., Stuntz, C. P., Bhalla, J. A., Bolter, N. D., \& Price, M. S. (2013). More than a game: Impact of The First Tee life skills programme on positive youth development: Project introduction and year 1 findings. Qualitative Research in Sport, Exercise and Health, 5(2), 214-244. doi:10.1080/2159676X.2012.712997

Wilkinson, D. L., Beaty, C. C., \& Lurry, R. M. (2009). Youth violence-crime or self-Help? Marginalized urban males' perspectives on the limited efficacy of the criminal justice system to stop youth violence. The ANNALS of the American Academy of Political and Social Science, 623(1), 25-38. doi: $10.1177 / 0002716208330484$

Zweig, J. M. (2003). Vulnerable youth: Identifying their need for alternative educational settings. Washington, DC: The Urban Institute. 